\title{
Immunochemistry of the Type Antigens of Streptococcus faecalis
}

\author{
By J. M. N. WILLERS AND M. F. MICHEL \\ The Laboratory of Microbiology, State University, Catharijnesingel 59, \\ Utrecht, The Netherlands
}

(Received 15 October 1965)

\begin{abstract}
SUMMARY
Serologically active fractions from 8 strains of Streptococcus faecalis, each with a different type antigen, were obtained by partial purification on a DEAE-cellulose column. By qualitative analysis of the hydrolysates of these fractions it was shown that glucose and glucosamine were always present, galactosamine and galactose were generally present. Arabinose was present as a minor component in some cases, whereas rhamnose was never found. Some evidence suggested that the glucose present in these hydrolysates was at least partly derived from the group D teichoic acid. $N$-acetylglucosamine or $N$-acetylgalactosamine and their corresponding hexoses were the main inhibitors of the quantitative precipitin reaction in 4 out of 8 type antigen systems investigated. In the type 19 system the two $\mathrm{N}$-acetylhexosamines but no other sugars were inhibitory. No inhibition by simple sugars was observed with the remaining three systems. The conditions required to obtain serologically active extracts are discussed. Two kinds of inhibitors formed during $\mathrm{HCl}$ extraction were isolated.
\end{abstract}

\section{INTRODUCTION}

Streptococcus faecalis strains can be classified into a number of serological types. By comparison of the results obtained by several investigators Sharpe (1964) proposed a classification into 11 type antigens. Elliot (1960) showed that the type antigens of three different $S$. faecalis types were located in the cell wall. Sharpe (1964) confirmed this observation for 20 strains of $S$. faecalis belonging to 11 serological types, and concluded that the type antigens were carbohydrates because they were destroyed by treatment with periodate. Maxted \& Fraser (1964) found that extracts made with $0.05 \mathrm{~N}-\mathrm{HCl}$ sometimes gave no precipitation with homologous type sera, but that the precipitate obtained from such extracts with acid ethanol contained serologically active material, while the supernatant fluid contained an acetone-insoluble material which inhibited the precipitin reaction. Extracts made with $0.01 \mathrm{~N}-\mathrm{HCl}$ were always serologically active.

In several group D streptococci the identity of the group D antigen and intracellular teichoic acid was demonstrated by Wicken, Elliot \& Baddiley (1963). Chemical analysis of the teichoic acid showed it to contain glycerol phosphate and di- and tri-glucosyl residues attached to most of the glycerol units. The treatment of Streptococcus faecalis with acid gives rise to extracts which contain both type antigen and teichoic acid (group antigen).

The present work was designed to give an immunochemical approach to the 
serological classification of the 8 apparently most common type antigens of Streptococcus faecalis strains. Qualitative analyses of the sugar components of the type antigens were made by paper chromatography. Information about the determinant group of most of these type antigens was obtained by inhibition of the quantitative precipitin reaction with simple sugars.

\section{METHODS}

Organisms. The following strains of Streptococcus faecalis were used: strain N 37 (type 1), strain 161 (type 3), strain GB 121 (type 4), strain N 83 (type 5), strain B (type 6), strain I.A.s. (type 8), strain N 97 (type 9), strain D 36 (type 19). These and their respective antisera were obtained from Mr W. R. Maxted, Central Public Health Laboratory, Colindale, London. Strain D 76 (type 1), containing relatively large amounts of teichoic acid, was obtained from Dr M. Elisabeth Sharpe (University of Reading).

Preparation of antisera. Antisera were prepared and absorbed as described by Sharpe \& Shattock (1952). Anti-pneumococcal sera were obtained from Dr E. Lund, Statens Seruminstitut, Copenhagen.

Extracts. Strains were grown in 81 . vol. of $0.5 \%$ glucose nutrient broth no. 2 (Oxoid) at $37^{\circ}$ for $24 \mathrm{hr}$. After harvesting, the cocci were washed once, resuspended in $320 \mathrm{ml} .0 .01 \mathrm{~N}-\mathrm{HCl}$ and heated for $15 \mathrm{~min}$. in a boiling water bath. After centrifugation the extraction procedure was repeated once with $100 \mathrm{ml} .0 .01 \mathrm{~N}-\mathrm{HCl}$. The extracts were pooled and dialysed against distilled water until neutral. When an extract was inactive with the homologous antiserum, the antigen was precipitated by the addition of $2.5 \mathrm{vol}$. of $96 \%$ ethanol in water and redissolved in distilled water after centrifugation.

Preparation of teichoic acid. Teichoic acid was prepared from strain D 76 as described by Wicken et al. (1963).

Purification of the extracts, hydrolysis, paper-chromatography and inhibition of the quantitative precipitin reaction. The methods of Willers, Michel, Sysma \& Winkler (1964) were used.

Isolation of inhibitors present in a non-reactive extract. The organisms from a 10-1. culture of the type 19 strain were successively extracted with $0.01 \mathrm{~N}-$ and $0.05 \mathrm{~N}-$ $\mathrm{HCl}$. The combined extracts were dialysed three times against distilled water and the diffusates were evaporated to dryness and redissolved in 3-5 ml. distilled water. This solution was used for paper chromatography and for inhibition reactions.

The dialysis residue was precipitated with 2.5 vol. $96 \%$ ethanol in water and the precipitate dissolved in distilled water. The addition of an equal volume of acetone to the ethanolic supernatant fluid gave also a precipitate which was soluble in distilled water (see Fig. 1.).

\section{RESULTS}

Extraction of antigens. After treatment with $0.01 \mathrm{~N}-\mathrm{HCl}$ only the strains of type 1, 3 and 6 gave serologically active extracts. The serological activity of non-reactive extracts was retested after precipitation with ethanol as described by Maxted \& Fraser (1964, 1966). Extracts from the strains of type 5, 9 and 19 then gave positive precipitin reactions with their antisera. As the extracts from the strains of types 4 
and 8 remained non-reactive even after ethanol treatment we tried to get a better antigen production by growing these strains at $24^{\circ}$ during $36 \mathrm{hr}$ as suggested by Sharpe \& Fewins (1960). Organisms grown at $24^{\circ}$ and extracted with $0.01 \mathrm{~N}-\mathrm{HCl}$ were again non-reactive. However, extraction of both organisms with $0.05 \mathrm{~N}-\mathrm{HCl}$ gave active extracts when the bacteria were grown either at $24^{\circ}$ or at $37^{\circ}$.

Purification. Chromatography on DEAE cellulose columns of the serologically active extracts gave no uniform results (Table 1 ). The serological activity of the extracts of type 5 and 6 strains was found in the distilled-water fractions, but the active fractions of other type antigens were eluted with phosphate buffer containing $0.1 \mathrm{M}-\mathrm{NaCl}$ or $0.25 \mathrm{M}-\mathrm{NaCl}$. The serological activity in the quantitative precipitin reaction was in all cases restricted to one fraction, indicating a moderate degree of purification. The percentages of the yield and protein content of the serological active fractions are as shown in Table 1. In the type antigens of group F streptococci obtained by formamide extraction, the serologically active fractions from the DEAE-cellulose column always had the lowest protein content (Willers et al. 1964), but in the present investigation a similar purification of the type antigens of Streptococcus faecalis gave a much less effective separation of serological activity and protein content.

Table 1. Distribution of the yield of serologically active material and protein content in DEAE-cellulose column fractions of Streptococcus faecalis strains carrying 8 different type antigens

$\begin{array}{cccc}\text { Strain } & \begin{array}{c}\text { Eluant containing } \\ \text { active fraction }\end{array} & \begin{array}{c}\text { Yield } \\ (\%)\end{array} & \begin{array}{c}\text { Protein } \\ (\%)\end{array} \\ \text { D1 } & \text { PB*+0.1 M-NaCl } & 9 & 48 \\ \text { D3 } & \text { PB+0.25 M-NaCl } & 8 \cdot 8 & 47 \\ \text { D4 } & \text { PB+0.1 M-NaCl } & 3 \cdot 2 & 28 \\ \text { D5 } & \text { Distilled water } & 10 \cdot 7 & 22 \\ \text { D6 } & \text { Distilled water } & 71 \cdot 4 & 13 \\ \text { D8 } & \text { PB+0.25 M-NaCl } & 20 \cdot 4 & 62 \\ \text { D9 } & \text { PB+0.25 M-NaCl } & 2 \cdot 8 & 24 \\ \text { D 19 } & \text { PB +0.25 M-NaCl } & 3 \cdot 9 & 26 \\ & * \text { PB } & \text { phosphate buffer } 0.0175 \text { M (pH 6.4). }\end{array}$

Reactions of teichoic acid. A 10 l. culture of Streptococcus faecalis strain D 76 (type 1) yielded $130 \mathrm{mg}$. teichoic acid. This teichoic acid gave a precipitate both with group $\mathrm{D}$ antiserum and with type antiserum. Treatment of the teichoic acid with $0.01 \mathrm{~N}-\mathrm{HCl}$ for $10 \mathrm{~min}$. at $100^{\circ}$ did not decrease either of these serological activities as measured in the capillary precipitin reaction. A similar treatment with $0.05 \mathrm{~N}$ $\mathrm{HCl}$ decreased the serological activities of the teichoic acid to only weak precipitin reactions with both group $\mathbf{D}$ and type 1 antisera. The teichoic acid which had been treated with $0.01 \mathrm{~N}-\mathrm{HCl}$ was precipitated with $2.5 \mathrm{vol}$. of ethanol and redissolved in distilled water. This solution was put on a DEAE-cellulose column. Serological tests of the eluates revealed that the distilled-water fraction contained both group $\mathrm{D}$ and type 1 antigen.

The serologically active fractions of the eight different Streptococcus faecalis types were tested against group $\mathbf{D}$ antiserum in the capillary ring reaction. The type $\mathbf{1}$ extract (strain $\mathrm{N} 37$ ) and the type 4 extract gave good precipitates with the antiserum, and the type 3 and type 9 extracts gave weak reactions. 
Qualitative analyses. The results of qualitative analysis of the serologically active fractions are given in Table 2. All contained glucose and glucosamine and all except the type 4 fraction contained galactosamine. Moreover most fractions contained galactose and possibly arabinose. No rhamnose was found. To confirm the absence of rhamnose and the possible presence of arabinose with a more sensitive method, one-dimensional chromatograms were run. Again no rhamnose was found, although $5 \%$ rhamnose in a sugar mixture can be detected. The presence of arabinose was suggested in four of the extracts.

Inhibition of the quantitative precipitin reaction. The serologically active fractions obtained from the DEAE-cellulose column were used as antigen in a quantitative precipitin reaction. Table 3 gives the results of the inhibitions by simple sugars and oligosaccharides. None of the sugars used gave any inhibition in the type 3, type 8

Table 2. Qualitative analyses of serologically active extracts of Streptococcus faecalis strains carrying different type antigens

$\begin{array}{lcccccccc}\text { Extract of type... } & \text { D1 } & \text { D3 } & \text { D4 } & \text { D5 } & \text { D6 } & \text { D8 } & \text { D9 } & \text { D19 } \\ \text { Glucose } & ++ & +++ & +++ & +++ & ++ & +++ & +++ & +++ \\ \text { Galactose } & + & ++ & ++ & - & ++ & - & ++ & - \\ \text { Glucosamine } & ++ & + & + & + & + & + & ++ & ++ \\ \text { Galactosamine } & ++ & +++ & - & + & ++ & ++ & ++ & + \\ \text { Arabinose } & + & + & + & - & - & + & - & -\end{array}$

Table 3. Inhibition by sugars of the quantitative precipitation between the type antigens of Streptococcus faecalis strains and their homologous antisera

\begin{tabular}{|c|c|c|c|c|c|c|c|c|}
\hline \multirow{2}{*}{ Extract of type... } & $\mathbf{D} \mathbf{1}$ & $\mathbf{D 3}$ & $\mathbf{D 4}$ & $\mathbf{D 5}$ & $\mathbf{D} 6$ & $\mathbf{D} 8$ & $\mathbf{D} 9$ & $\mathbf{D} 18$ \\
\hline & \multicolumn{8}{|c|}{ Concentration of sugar $(\mu \mathrm{M})$ for $\mathbf{5 0} \%$ inhibition } \\
\hline Glucose & 74 & . & - & $44 *$ & . & . & . & . \\
\hline$\alpha$-Methylglucoside & $\mathbf{2 7}$ & . & . & . & . & . & . & . \\
\hline Cellobiose & 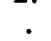 & . & . & $62^{*}$ & . & . & . & . \\
\hline Maltose & $\dot{.}$ & . & . & 23* & . & . & . & $\dot{.}$ \\
\hline Galactose & - & - & $59 \dagger$ & . & 74 & . & . & - \\
\hline$\alpha$-Methylgalactoside & . & . & $27 \dagger$ & . & 62 & . & . & . \\
\hline 2-Deoxygalactose & . & - & $65 \dagger$ & . & $81^{*}$ & . & . & . \\
\hline$\alpha$-Melibiose & . & . & $15 \dagger$ & - & 15 & . & . & . \\
\hline Stachyose & . & . & $12 \dagger$ & . & $32^{*}$ & . & . & - \\
\hline$N$-acetylglucosamine & 9 & . & . & $83^{*}$ & . & . & . & 62 \\
\hline$N$-acetylgalactosamine & - & . & 52 & . & 31 & . & . & 62 \\
\hline
\end{tabular}

* When $50 \%$ inhibition was not reached, the sugar concentration $(\mu \mathrm{M})$ for $30 \%$ inhibition is given.

$\dagger$ In some cases (D 4 ) the $80 \%$ inhibition values of $\mu \mathrm{M}$ sugar are given.

and type 9 systems. Both the $N$-acetylhexosamines were active in the type 19 system, whereas in other systems only one of them was inhibitory. When a $\mathrm{N}$ acetylhexosamine was active, the corresponding hexose and some of its derivatives were also good inhibitors. Though the type 4 and type 6 systems were inhibited by the same sugars, no cross-reactions of these were observed.

When both $N$-acetylhexosamine and the corresponding hexose are active inhibitors of a system, the possibility exists that the determinant group contains an 
$O$-acetylated hexose as terminal sugar (Uchida, Robbins \& Luria, 1963). To exclude this possibility in the type 1, 4, 5 and 6 systems, the antigens were mixed with an equal volume of $0.01 \mathrm{~N}-\mathrm{NaOH}$, left at room temperature for 20 and $60 \mathrm{~min}$. and finally neutralized with $\mathbf{0 . 0 1} \mathrm{N}-\mathrm{HCl}$. Comparison of the serological activity of both the treated and untreated antigens showed no loss in antibody-precipitating capacity.

Cross-reactions with other streptococcal antigens and with streptococcal and pneumococcal sera. $\mathrm{N}$-acetylglucosamine is known to be the terminal sugar of the group $\mathbf{A}$ streptococcal antigen (McCarty, 1958). As this sugar is an inhibitor in the type 1, 5 and 19 systems, cross-reactions between these systems and group A antiserum were investigated. No cross-precipitin reactions were found. Similarly type 4, 6 and 19 antigens of Streptococcus faecalis for which $\mathrm{N}$-acetylgalactosamine is an inhibitor were tested for cross-reactions with group $\mathrm{C}$ antiserum, which contains combining sites directed against $N$-acetylgalactosamine (Krause \& McCarty, 1962). A positive reaction was found between $S$. faecalis type 6 antigen and group $\mathrm{C}$ antiserum. Pneumococcal sera type II, VIa, VIII and XIV gave no cross-reactions with any of the type antigens of $\boldsymbol{S}$. faecalis. Globoside with the structure $N$-acetylgalactosaminoyl- $\beta$ - $(1 \rightarrow 3)$ galactosyl $(1 \rightarrow 4)$ galactosyl $(1 \rightarrow 4)$ glucosyl-sphingosine (Yamakawa, Nishimura \& Kamimura, 1965) was inactive in cross-reactions and did not give inhibitions in the $S$. faecalis type 4, 6 and 19 systems. (Globoside is a mucolipid of human erythrocytes or human kidney cells. It has blood-group ABO activity.)

Isolation of inhibitors present in the type 19 extract. The procedure as described in Methods is shown in Fig. 1. The extracts were tested in the capillary precipitin test. The initial extract (extract 1 ) gave a negative reaction, but became weakly positive after dialysis (extract 2). The addition of 2.5 vol. of ethanol to extract 2 yielded a precipitate which when dissolved in a volume of water equal to the volume of extract 2 gave a strong capillary precipitin reaction (extract 3 ). Two kinds of inhibitors were obtained. The low molecular-weight inhibitor (inhibitor 1), which

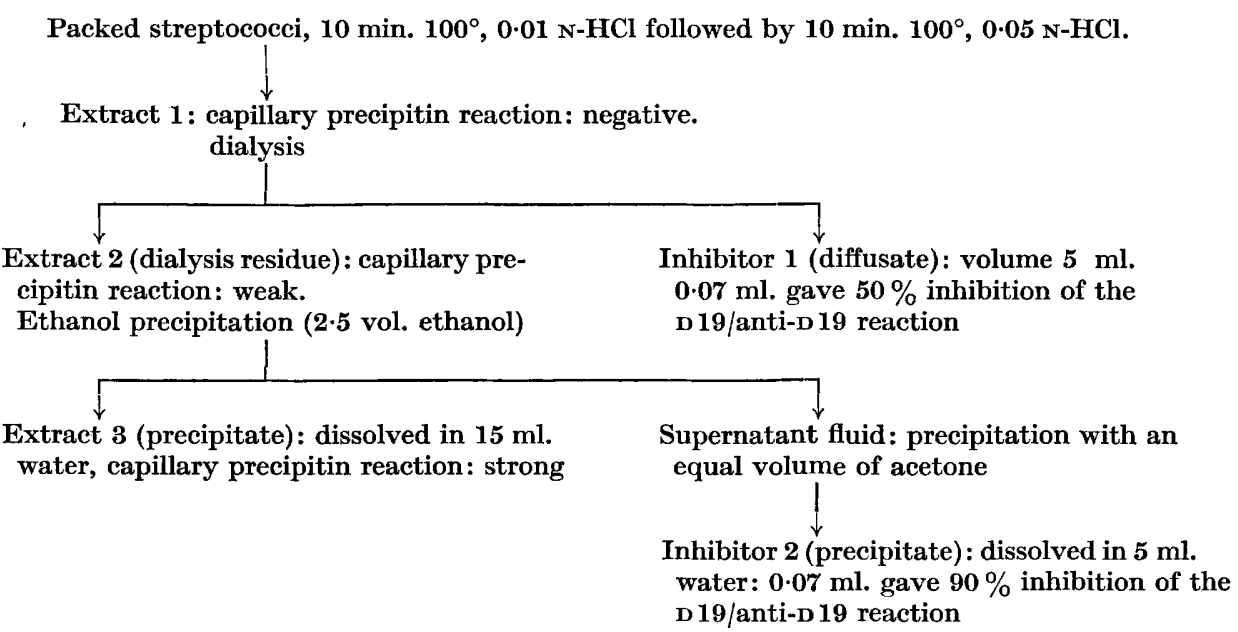

Fig. 1. Procedure followed for the isolation of two inhibitors from an extract of a Streptococcus faecalis type 19 strain. 
was fairly active, was found in the dialysis residue of extract 1. A second kind of inhibitor was isolated from extract 2, the supernatant fluid remaining after ethanol precipitation of the type-specific material was treated with acetone, and the resulting precipitate redissolved. Inhibitor 2 was much more active than inhibitor 1.

\section{DISCUSSION}

Chromatography on DEAE-cellulose was much less effective for the separation of type-specific antigenic material from protein in hydrochloric acid extracts of group D streptococci than in formamide extracts of group F streptococci (Willers et al. 1964). Moreover, the protein content and the dry weight of each serologically active fraction varied appreciably with the different type antigens. The results of qualitative analysis of the purified type antigens of group D streptococci differed in several respects from the results of analyses of the group antigens of A (McCarty, 1952), C (Krause \& McCarty, 1962), F (Willers et al. 1964) and G streptococci (Curtis \& Krause, 1963), and of the type antigens of group F streptococci (Willers et al. 1964). In the latter antigens rhamnose is a major component of the polysaccharide, but in the type antigens of group $D$ no rhamnose was detected by paper chromatography.

Rhamnose is a component of the cell wall of streptococci of group D (Jones \& Shattock, 1960) as well as of all the other common groups of streptococci that have been investigated (Slade \& Slamp, 1962). The same sugar was also found in typespecific antigenic material from the three different strains of Streptococcus faecalis by Elliott (1960), and in a type 1 strain by Bleiweis \& Krause (1965). These authors obtained their material by enzyme treatment of cell walls. The absence of rhamnose from the hydrolysates of the purified serologically active fractions strongly supports the view that this sugar, though present in the cell wall, forms no part of the type antigen molecule. Recently Wittner \& Hayashi (1965) described the isolation of type specific polysaccharides from cell walls of group B streptococci, which did not contain rhamnose. A second point of difference is the evidence of the presence of arabinose in extracts from a number of $S$. faecalis types. This sugar was not found in the cell wall of group D streptococci by Jones \& Shattock (1960) or by Cummins \& Harris (1956). The discrepancies in these observations may be ascribed to the differences in the strains investigated and in the methods used for the preparation of the antigenic material.

It was shown that the teichoic acid and the type antigen of Streptococcus faecalis strain $\mathrm{D} 76$ were extracted together with a cold trichloroacetic acid solution and were not separated by the treatment with acid ethanol and acetone nor by the DEAEcellulose column fractionation. It was further shown that the group $\mathbf{D}$ antigen was present in a number of type antigen extracts prepared with $\mathbf{0 \cdot 0 1} \mathrm{N}-\mathrm{HCl}$. Therefore the strong glucose spot shown in all chromatograms of the hydrolysates of the acid extracts of the 8 different $S$. faecalis types may at least be derived partly from the group $D$ antigen.

Inhibition of the quantitative precipitin reaction by simple sugars was observed only with 5 of the 8 type antigens. In the type 1 system, an $\alpha$-glucosidic group and $N$-acetylglucosamine appear to be part of the determinant group. Recently Bleiweis $\&$ Krause (1965) observed these sugars to be inhibitory in the type 1 system. In 
the type 5 system $\mathrm{N}$-acetylglucosamine and glucose and its derivatives cellobiose and maltose are inhibitors, but there is no evidence about the kind of linkage. In the same way, the inhibition found in the type 4 and type 6 systems point to the presence of an $\alpha$-galactosidic moiety and $N$-acetylgalactosamine in the determinant group. The simultaneous activity as inhibitors of hexoses and the corresponding hexosamines of the type 1, 4, 5 and 6 antigens, suggested the presence of $O$-acetyl residues in the determinant group, but the insensitivity of these antigens to 0.01 $\mathrm{N}-\mathrm{NaOH}$ treatment practically excluded this possibility.

Important information about structures of determinant groups can often be obtained from cross-reactions with sera possessing combining sites directed against determinants of known composition. None of the Streptococcus faecalis type specific products gave cross-reactions with pneumococcal sera for types II, VIa, VIII or XIV, or with group A antiserum. One of them (type 6) did, however, react with the group $\mathrm{C}$ antiserum. As the reactions between type 6 and type 4 antigens and their homologous antisera are not inhibited by globoside containing a terminal $\beta-N$ acetylgalactosamine group, the presence of a $N$-acetylgalactosamine in the $\alpha$ configuration in type 6 and type 4 antigens has to be considered.

To obtain from all the cultures extracts of sufficient potency for use in the quantitative precipitin reaction we had to use three different methods of extraction with hydrochloric acid. These results appear to be at variance with the finding of Maxted \& Fraser $(1964,1966)$ that all strains gave serologically active extracts with 0.01 N-HCl. When we used their small-scale method we obtained results similar to theirs. For use in a quantitative precipitin reaction more concentrated extracts are needed. In preparing such extracts from the deposit from 8-1. cultures different methods were necessary. In the case of types 1,3 and 6 the hydrolysis with $0.01 \mathrm{~N}-$ $\mathrm{HCl}$ split enough type antigen and only few inhibiting molecules to give a good precipitin reaction. Of the types 5,9 and 19 so much inhibiting material was produced that removal of these inhibitors was necessary before a sufficiently strong precipitin reaction could be obtained. The hydrolysis conditions for the type 4 and 8 organisms were possibly too weak to dissolve sufficient antigen for a quantitative precipitin reaction.

The difference between the strains which gave reactive and non-reactive extracts on treatment with $0.01 \mathrm{~N}-\mathrm{HCl}$ can be explained by the fact that during the extraction of the latter strains fragments were released which inhibited the antigen-antibody reaction. This was further shown since during the extraction of the type 19 bacteria two kinds of fragments were isolated. Both materials caused strong inhibition and behaved on paper chromatograms as mixtures of oligosaccharides. Inhibitors of small molecular size were obtained by dialysis whereas larger inhibitors could be precipitated with acetone.

The authors thank Mr W. R. Maxted for suggesting this investigation. They are indebted to Professor Dr K. C. Winkler for constant advice and to Professor Dr T. Yamakawa (Institute for Infectious Diseases of the University of Tokyo) for a very generous gift of globoside. Part of the work was supported financially by the Netherlands Organization for the Advancement of Pure Research (Z.W.O.). The skilful technical assistance of Mr P. K. Storm and Mr H. J. M. Messerschmidt is gratefully acknowledged. 


\section{REFERENCES}

Bleiweis, A. S. \& Krause, R. M. (1965). The cell walls of group D streptococci. I. The immunochemistry of the type 1 carbohydrate. J. exp. Med. 122, 237.

Cummins, C. S. \& Harris, H. (1956). The chemical composition of the cell wall in some Gram-positive bacteria and its possible value as a taxonomic character. J. gen. Microbiol. 14, 583.

Curtis, S. N. \& KraUSE, R. M. (1964). Immunochemical studies on the cell walls of group G haemolytic streptococci. Fed. Proc. 22, 205.

Exliott, S. D. (1960). Type and group polysaccharides of group D streptococci. J. exp. Med. 111, 621 .

Jones, D. \& Shatrock, P. M. F. (1960). The location of the group antigen of group D streptococcus. J. gen. Microbiol. 23, 335.

Krause, R. M. \& McCarty, M. (1962). Studies on the chemical structure of the streptococcal cell wall. II. The composition of group $\mathrm{C}$ cell walls and chemical basis for serologic specificity of the carbohydrate moiety. J. exp. Med. 115, 49.

McCARTY, M. (1952). The lysis of group A hemolytic streptococci by extracellular enzymes of Streptomyces albus. I. Production and fractionation of the lytic enzymes. J. exp. Med. 96, 555 .

MCCARTY, M. (1958). Further studies on the chemical basis for serological specificity of group A streptococcal carbohydrate. J. exp. Med. 108, 311.

MaXted, W. R. \& Fraser, C. A. M. (1964). The serological typing of Streptococcus faecalis. Zentbl. Bakt.ParasitKde, Abt. 2, 196, 76.

MaXted, W. R. \& Fraser, C. A. M. (1966). Sensitivity to acid of the type antigens of Streptococcus faecalis. J. gen. Microbiol. 43, 145.

Sharpe, M. E. (1964). Serological types of Streptococcus faecalis and its varieties and their cell wall type antigen. J. gen. Microbiol. 36, 151.

Sharpe, M. E. \& Fewins, B. G. (1960). Serological typing of strains of Streptococcus faecium and unclassified group D streptococci isolated from canned hams and pig intestines. J. gen. Microbiol. 23, 621.

Sharpe, M. E. \& Shattock, P. M. F. (1952). The serological typing of group D streptococci associated with outbreaks of neonatal diarrhoea. J. gen. Microbiol. 6, 150.

Slade, H. D. \& Slamp, W. C. (1962). Cell-wall composition and the grouping antigens of streptococci. J. Bact. 84, 345.

Uchida, T., Robbins, P. W. \& Luria, S. E. (1963). Analysis of the serologic determinant groups of the Salmonella E group O-antigens. Biochemistry, 2, 663.

Wicken, A. J., Elliott, S. D. \& Baddiley, J. (1963). The identity of streptococcal group D antigen with teichoic acid. J. gen. Microbiol., 31, 231.

Willers, J. M. N., Michel, M. F., Sysma, M. J. \& Winkler, K. C. (1964). Chemical analysis and inhibition reactions of the group and type antigens of group $F$ streptococci. J. gen. Microbiol. 36, 95.

WitTNER, M. K. \& HaYashi, J. A. (1965). Studies of streptococcal cell walls. VII. Carbohydrate composition of group B cell walls. J. Bact. 89, 398.

Yamakawa, T., Nishimura, S. \& Kamimura, M. (1965). The chemistry of the lipids of posthemolytic residue or stroma of erythrocytes. XIII. Further studies on human red cell glycolipids. Jap. J. exp. Med. 35, 201. 